\title{
Synthetic Ground-Motion Simulation Using a Spatial Stochastic Model with Slip Self-Similarity: Toward Near-Source Ground-Motion Validation
}

\author{
Ya-Ting Lee ${ }^{1, *}$, Kuo-Fong Ma ${ }^{1}$, Ming-Che Hsieh ${ }^{2}$, Yin-Tung Yen ${ }^{2}$, and Yu-Sheng Sun ${ }^{1}$ \\ ${ }^{I}$ Department of Earth Sciences and Graduate Institute of Geophysics, National Central University, Taoyuan City, Taiwan, R.O.C. \\ ${ }^{2}$ Sinotech Engineering Consultants, Inc., Taipei, Taiwan, R.O.C.
}

Received 2 September 2015, revised 24 November 2015, accepted 27 November 2015

\begin{abstract}
Near-fault ground motion is a key to understanding the seismic hazard along a fault and is challenged by the ground motion prediction equation approach. This paper presents a developed stochastic-slip-scaling source model, a spatial stochastic model with slipped area scaling toward the ground motion simulation. We considered the near-fault ground motion of the 1999 Chi-Chi earthquake in Taiwan, the most massive near-fault disastrous earthquake, proposed by Ma et al. (2001) as a reference for validation. Three scenario source models including the developed stochastic-slip-scaling source model, meanslip model and characteristic-asperity model were used for the near-fault ground motion examination. We simulated synthetic ground motion through 3D waveforms and validated these simulations using observed data and the ground-motion prediction equation (GMPE) for Taiwan earthquakes. The mean slip and characteristic asperity scenario source models over-predicted the near-fault ground motion. The stochastic-slip-scaling model proposed in this paper is more accurately approximated to the near-fault motion compared with the GMPE and observations. This is the first study to incorporate slipped-area scaling in a stochastic slip model. The proposed model can generate scenario earthquakes for predicting ground motion.
\end{abstract}

Key words: Scenario source model, Slip scaling, Asperity, Ground-motion prediction, Near-fault motion

Citation: Lee, Y. T., K. F. Ma, M. C. Hsieh, Y. T. Yen, and Y. S. Sun, 2016: Synthetic ground-motion simulation using a spatial stochastic model with slip self-similarity: Toward near-source ground-motion validation. Terr. Atmos. Ocean. Sci., 27, 397-405, doi: 10.3319/TAO.2015.11.27.01(TEM)

\section{INTRODUCTION}

Ground-motion prediction is particularly crucial for seismic hazard assessments. Ground-motion prediction equations (GMPEs), widely adopted to determine ground motion, are acquired through regression analyses of large ground-motion data collections from past earthquakes. GMPEs can estimate ground motion using variables such as earthquake magnitude, distance and site classification. GMPE predictions are rather straightforward, but with fewer constraints on near-fault ground motion. Few nearfault ground-motion data might be insufficient for GMPE regression. Deterministic ground-motion prediction, prediction using earthquake scenario simulations, is attracting much research interest. To reliably simulate these scenarios requires comprehensive knowledge of fault models, especially knowledge of the geometry and slip heterogeneity of finite faults (Liao et al. 2016; Wen et al. 2016).

\footnotetext{
* Corresponding author

E-mail: shine2530@gmail.com
}

The source scaling of earthquake dimensions has been investigated in several studies (Romanowicz 1992; Scholz 1994; Wells and Coppersmith 1994; Wang and Ou 1998; Mai and Beroza 2000; Manighetti et al. 2005, 2007; Wesnousky 2008; Klinger 2010; Yen and Ma 2011). Pegler and Das (1996) defined fault length using aftershock patterns and suggested a similar scaling relationship for strike-slip crustal events. Mai and Beroza (2000) defined the effective source dimensions of a finite-fault model using the spatial autocorrelation scheme to investigate source dimension scaling. Irikura and Miyake (2011) developed a recipe for predicting strong ground motions by characterizing the source model for future crustal earthquakes. In addition, they suggested that the slip distribution on a finite fault is the major concern in the forward simulation of earthquake scenarios. To define finite-fault heterogeneity Somerville et al. (1999), Murotani et al. (2008), and Lee et al. (2016) examined earthquakes in California, Japan, and Taiwan, respectively. They reported that in approximately $20 \%$ of the 
total fault rupture area, the slips are 1.5 times larger than the average slip. This area, named the area of combined asperities, is considered the area most responsible for generating extreme ground-motion acceleration.

Lee et al. (2016) analyzed the slip area as a function of slip and found that the fault slip exhibited self-similar scaling between the rupture slip and slip area. For $\mathrm{M}_{\mathrm{w}}>7.0$ earthquakes, slip-distribution scaling in the finite-fault model is similar to $\log R_{s}=-0.69 R_{d}+0.09$, where $R_{d}$ is the ratio of the slip to the mean slip, and $R_{s}$ is the ratio of the fault area to the effective area. The self-similarity of earthquake slip distributions has been discussed (Manighetti et al. 2005, 2007; Wesnousky 2008; Klinger 2010; Lee et al. 2016) and applied to rupture simulations. Ide and Aochi $(2005,2013)$ and Aochi and Ide $(2009,2011)$ proposed a model for the wide-scale growth of dynamic rupture during an earthquake. They used a multiscale heterogeneous model for simulating the Tohoku-Oki earthquake rupture.

We adopted the spatial autocorrelation scheme proposed by Mai and Beroza (2000) in this study to define the effective fault dimensions of the slip model. We considered the scaling of the slipped area partitioned within the finite fault for slip-distribution heterogeneity (Lee et al. 2016). We considered finite-fault slip-heterogeneity scaling to constrain the near-fault ground motion in the simulation. We validated the simulated near-fault ground motion using the 1999 Chi-Chi earthquake as the reference because of the availability of a large data set and comprehensive near-fault motion records for this earthquake. Synthetic seismograms were generated by simulating 3D waveforms. The groundmotion simulations of the mean slip, characteristic asperity, and stochastic-slip-scaling models were compared and validated using the empirical attenuation equation of Lin et al. (2012). The results indicated that the stochastic-slip-scaling model is the model most consistent with the observations and the GMPE, particularly for near-fault motion.

\section{GROUND MOTION SIMULATION OF THE 1999 CHI-CHI EARTHQUAKE}

The 1999 Chi-Chi earthquake, the largest earthquake in Taiwan in the twentieth-century, struck Central Taiwan on 20 September 1999 and caused substantial loss of life and economic damage. It ruptured along the Chelungpu fault with a surface rupture of approximately $100 \mathrm{~km}$ (CGS 1999) and a moment magnitude, $M_{w}$, of 7.7 (Ma et al. 2001). Its hypocenter was at $23.853^{\circ} \mathrm{N}$ and $120.816^{\circ} \mathrm{E}$ at a depth of $8 \mathrm{~km}$ (Fig. 1). We used the finite-fault slip model proposed by Ma et al. (2001) for the 1999 Chi-Chi earthquake as a reference (Fig. 2). The slip model is based on the inversion of high-quality near-source strong-motion records and broadband teleseismic displacement waveforms. The strike, dip, and rake of the 1999 Chi-Chi earthquake are 5, 30, and $55^{\circ}$, respectively.

\subsection{Characterizing Slip Models for Source Parameters}

The spatial autocorrelation scheme proposed by Mai and Beroza (2000) was adopted to define the effective fault dimensions (length and width) for the slip models. We considered a spatial slip function along the strike direction, in which the slips on each subfault along the dip direction were summed. Similarly, a spatial slip function along the dip was obtained by summing the slip on each subfault along the strike direction. The spatial slip function is defined as $f$ in Eq. (1). Furthermore, an autocorrelation method was used to estimate the effective dimensions of two spatial functions in the strike and dip directions. The estimated effective dimensions of the slip model for the 1999 Chi-Chi earthquake is shown in Fig. 2 (Yen and Ma 2011); the effective dimensions are defined as follows (Bracewell 1986):

$W^{A C F}=\frac{\int_{-\infty}^{\infty}\left(f^{*} f\right) d x}{\left.f^{*} f\right|_{x=0}}$

where $W^{A C F}$ denotes the effective dimensions of the lengths along the strike and dip directions, respectively. The mean slip is defined using the relationship between the seismic moment and the source dimensions:

$M_{0}=\mu L_{e} W_{e} d_{m}$

where $\mu$ is the rigidity of the crustal rock $\left(3 \times 10^{11} \mathrm{Nm}^{-2}\right)$, $L_{e}$ and $W_{e}$ are the effective length and width, respectively, and $d_{m}$ is the average effective slip (the mean slip referred to earlier in the text). The effective length and width of the 1999 Chi-Chi earthquake were estimated at 63 and $35 \mathrm{~km}$, respectively (Fig. 2), and the mean slip was $7.1 \mathrm{~m}$ (Yen and Ma 2011).

\subsection{Wavenumber Spectrum Analysis}

The stochastic characterization of the spatial complexity of the earthquake slip proposed by Somerville et al. (1999) and Mai and Beroza (2002) was applied to characterize the spatial variation in the slip for the proposed model. We analyzed the 2D Fourier transform of the slip model having a spatially random slip distribution. The $1999 \mathrm{Chi}-$ Chi earthquake is simulated in this study. Based on the Chelungpu fault surface rupture (approximately $100 \mathrm{~km}$; CGS 1999); the dimensions of the slip model are approximate 1.5 times the effective length and width. Therefore, the length and width of the finite fault are 94 and $52 \mathrm{~km}$, respectively. The slip in the initial slip model is first randomly distributed (Fig. 3a). Spatial 2D filters are subsequently applied to model the wavenumber amplitude spectrum. The wavenumber amplitude, $\operatorname{amp}(k x, k y)$, is calculated as follows 
(Somerville et al. 1999):

$$
\operatorname{amp}(k x, k y)=\frac{1}{\sqrt{1+\left[\left(\frac{-k x}{K C_{x}}\right)^{2}+\left(\frac{-k y}{K C_{y}}\right)^{2}\right]^{2.0}}}
$$

The spectrum falls off as the inverse square of the wavenumber at high wavenumbers; $k x$ and $k y$ are the normalized wavenumbers along the strike and dip, respectively. The slip distributions follow $k^{-2}$ decay in the wavenumber do- main. $K C$ is the inverse of the fault dimension (i.e., length along strike and width along dip). Figure $3 b$ illustrates the slip distribution of the stochastic model with the $k^{-2}$ decay in the wavenumber domain. With self-similarity in the slip distribution the spatial stochastic fault model is consistent with the model of Herrero and Bernard (1994). Furthermore, it is consistent with the fractal model of Frankel (1991) in which the fractal dimension was 2 .

Finally, we scaled the slipped area partitioned within the finite fault proposed by Lee et al. (2016) for slip-distribution heterogeneity. For large earthquakes with $\mathrm{M}_{\mathrm{w}}>7.0$,

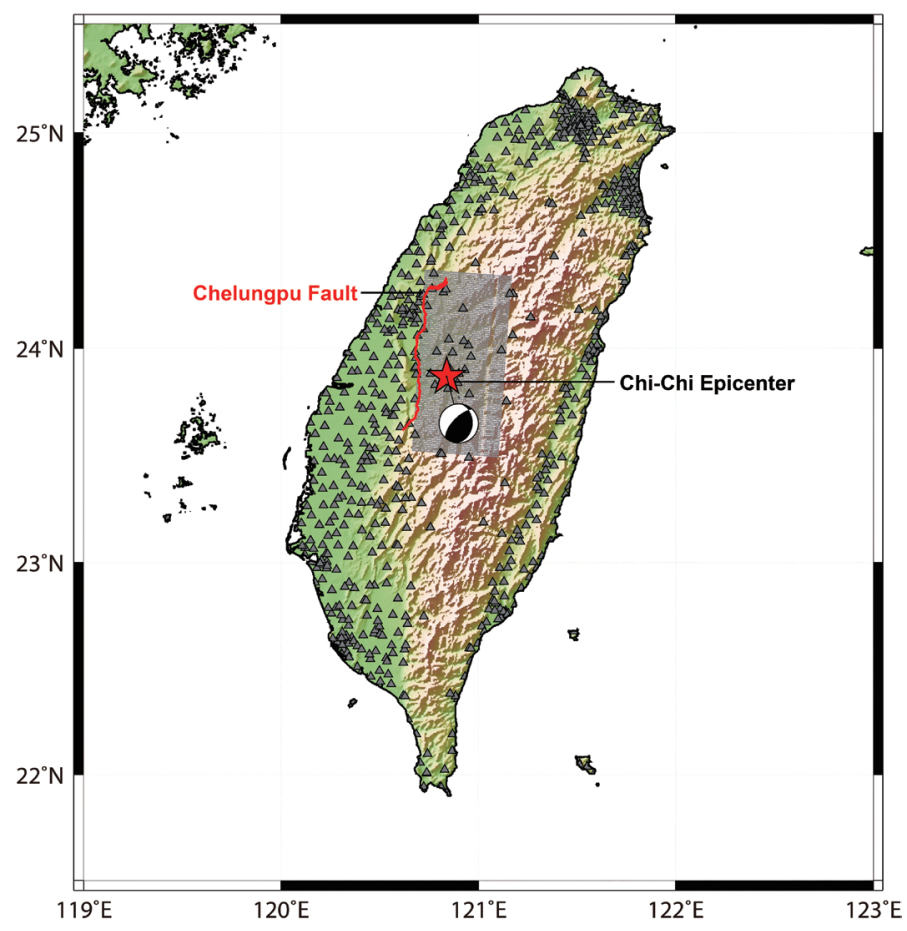

Fig. 1. Location of the 1999 Chi-Chi earthquake and the corresponding focal mechanisms; the source region is highlighted in grey. Grey triangles represent the distribution of strong-motion stations of the Taiwan Strong Motion Instrumentation Program (TSMIP). (Color online only)

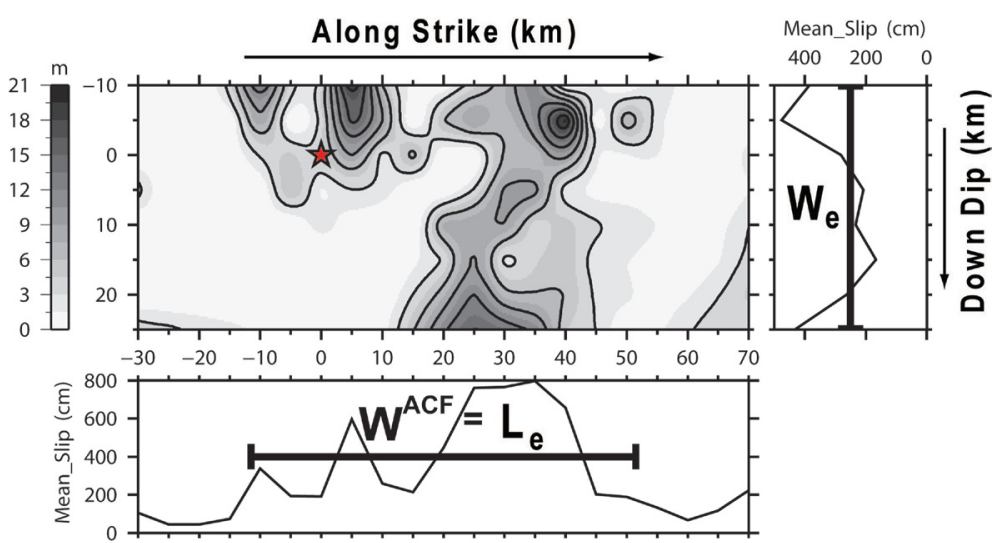

Fig. 2. Illustration of the effectiveness of the fault length and width estimated using the slip model (Ma et al. 2001) of the 1999 Chi-Chi earthquake. The top depth of the fault is set to zero. Two slip functions were obtained by summing the slip of each subfault along the down-dip and strike directions. They were used to obtain the effective fault width $\left(W_{e}\right)$ and length $\left(L_{e}\right)$, respectively (Yen and Ma 2011). (Color online only) 

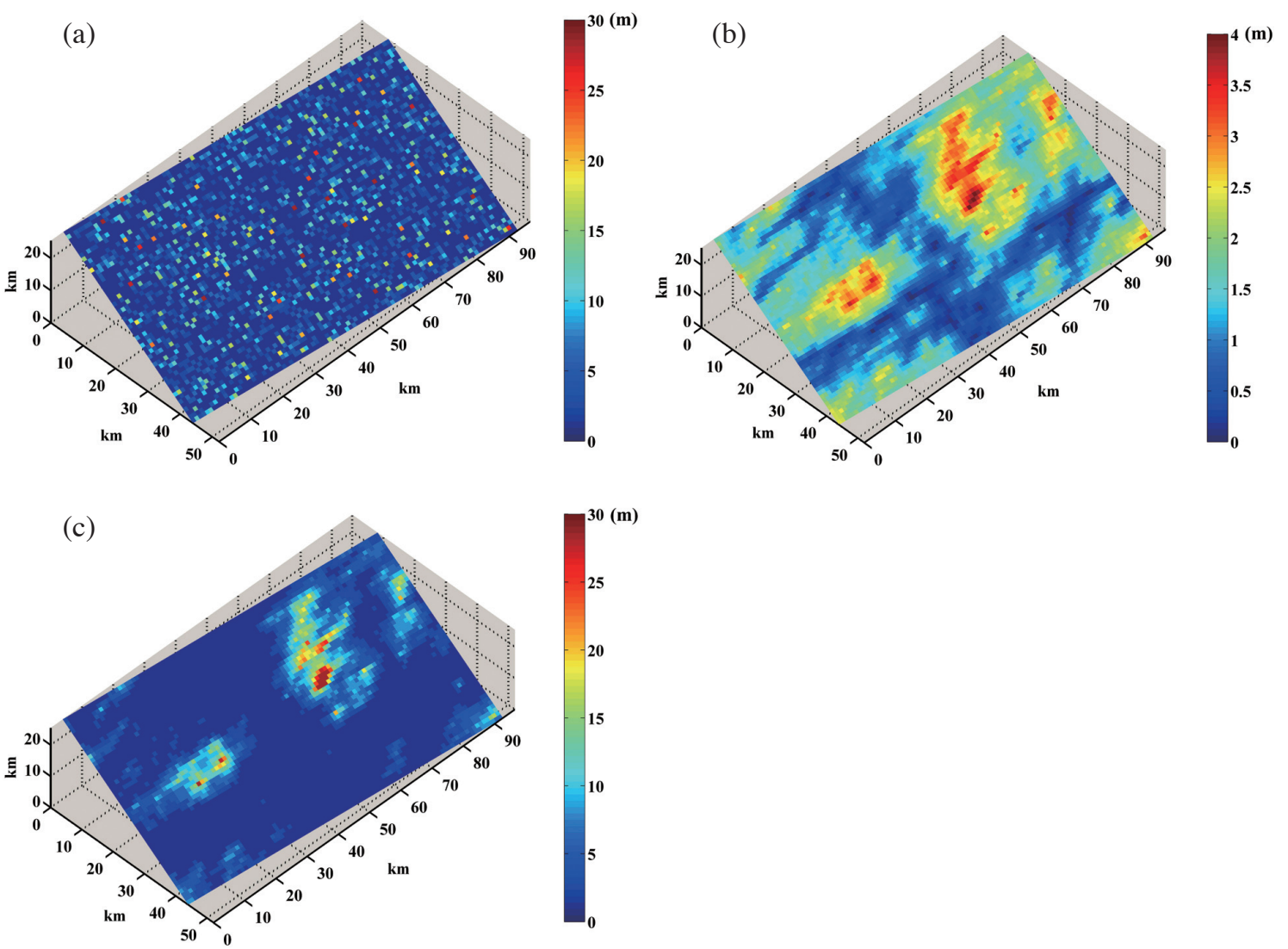

Fig. 3. Example of the scenario earthquake slip model. (a) Slip distribution with random spatial distribution; (b) slip distribution of the stochastic model with a $k^{2}$ decay in the wavenumber domain; and (c) slip distribution of the stochastic model with the normalized slip scaling obtained by Lee et al. (2016). (Color online only)

the relationship of the average area ratio $R_{s}$ as a function of the slip ratio $R_{d}$ is

$\log R_{s}=-0.69 R_{d}+0.09$

where $R_{d}$ is the ratio of the slip, $d$, to the mean slip, $d_{m}$ (i.e., $\left.d / d_{m}\right)$ and $R_{s}$ is the ratio of the fault area, $A$, with $d>R_{d} \times d_{m}$ to the effective area, $A_{e}$ (i.e., $A / A_{e}$ ). Accordingly, we normalized the slip scaling in the scenario slip model, as shown in Fig. 3c. This spatial stochastic model with slip scaling is termed the "stochastic-slip-scaling model" in this paper.

\subsection{Scenario Models of the 1999 Chi-Chi Earthquake}

For comparison we simulated the 1999 Chi-Chi earthquake ground motion using three scenario source models: the mean slip, characteristic asperity, and stochastic-slipscaling models. The mean slip model dimension referred to section 2.1 that is a $63 \times 35 \mathrm{~km}$ (effective length $\times$ effective width) fault plane, with a mean slip of $7.1 \mathrm{~m}$ (Fig. 4a). In the characteristic asperity model $20 \%$ of the fault plane area is considered the asperity area with its slip equaling 1.5 times the mean slip (Fig. 4b). The fault plane dimensions are the same as the effective length and width. In the third model we simulated the ground motion using the stochastic-slipscaling model (Fig. 4c) discussed in section 2.2. This model is an arbitrary stochastic slip model in which the fault plane dimensions equal 1.5 times the effective length and width. The stochastic slip distribution follows the slip scaling presented in Eq. (4).

\subsection{Wave Simulation Through the 3D Finite-Difference Scheme}

The synthetic ground motions for the scenario earthquakes were generated through 3D waveform simulation (Zhang and Chen 2006; Hsieh et al. 2014). Zhang and Chen (2006) developed a traction-image finite-difference algorithm involving 3D simulation and surface topography. Hsieh et al. (2014) applied the algorithm to Taiwan for source inversion. They used a 3-D velocity structure based on the tomography model for the Taiwan region developed by Kuo-Chen et al. (2012) and ETOPO1 (Amante and Eakins 2009) for the surface topography which has a resolution of 1-arc-minute (about $1.85 \mathrm{~km}$ ). The topography model horizontal grid spacing was resampled to $300 \mathrm{~m}$ using nearest point interpolation for their finite-difference 
mesh (Hsieh et al. 2014). Hsieh et al. (2014) constructed 5 layers from the surface to a depth of $60 \mathrm{~km}$ (Table 1) to gently deform grids in the curvilinear coordinate. The horizontal grid spacing from the mesh top to bottom is a constant $300 \mathrm{~m}$ with a variable vertical spacing from $171 \mathrm{~m}$ near the surface to $783 \mathrm{~m}$ at $60-\mathrm{km}$ depth. The source-time function for simulating the waveform is a Gaussian function with a characteristic width of $2 \mathrm{~s}$. This function yields waveforms with frequency content of up to $0.8 \mathrm{~Hz}$. Rupture speed is a constant equal to $2.4 \mathrm{~km} \mathrm{~s}^{-1}$, which is $80 \%$ of the shear-wave speed $\beta\left(=3.0 \mathrm{~km} \mathrm{~s}^{-1}\right)$. The methodology of 3D simulation was detailed by Hsieh et al. (2014).

\section{RESULT}

We calculated the peak ground velocity (PGV) of the simulated synthetic waveforms to characterize the groundmotion amplitude. We used PGV to characterize the amplitude because of its low sensitivity to high-frequency components (Baumann and Dalguer 2014). Figures 5a - c present the shaking maps simulated using the mean slip, characteristic asperity, and stochastic-slip-scaling source models. The mean slip and characteristic asperity models simulated higher PGV values than did the stochastic-slipscaling model.

We considered the GMPE constructed by Lin et al. (2012) to compare the simulation results with the empirical attenuation equation. They constructed a local GMPE using abundant seismic data from Taiwan earthquakes. The equation accounts for physical properties, including the source, geometric spreading, inelastic attenuation, and site effect in describing the ground motion:

$$
\begin{aligned}
& \operatorname{lnPGV}=\mathrm{C}_{1}+\mathrm{F}_{1}+\mathrm{C}_{3}\left(8.5-\mathrm{M}_{\mathrm{w}}\right)^{2} \\
& +\left[\mathrm{C}_{4}+\mathrm{C}_{5}\left(\mathrm{M}_{\mathrm{w}}-6.3\right)\right] \ln \left[\sqrt{\mathrm{R}^{2}+\exp (\mathrm{H})^{2}}\right] \\
& +\mathrm{C}_{6} \mathrm{~F}_{\mathrm{NM}}+\mathrm{C}_{7} \mathrm{~F}_{\mathrm{RV}}+\mathrm{C}_{8} \ln \left(\mathrm{V}_{\mathrm{S} 30} / 1130\right) \\
& \mathrm{F}_{1}=\mathrm{C}_{2}\left(\mathrm{M}_{\mathrm{w}}-6.3\right) \quad \text { where } \mathrm{M}_{\mathrm{w}} \leq 6.3 \\
& \mathrm{~F}_{1}=\left(-\mathrm{HC}_{5}\right)\left(\mathrm{M}_{\mathrm{w}}-6.3\right) \quad \text { where } \mathrm{M}_{\mathrm{w}}>6.3
\end{aligned}
$$

where $\mathrm{C}_{1}$ to $\mathrm{C}_{8}$ are the regression coefficients $\left(\mathrm{C}_{1}=4.9947\right.$, $\mathrm{C}_{2}=0.7665, \mathrm{C}_{3}=0, \mathrm{C}_{4}=-1.0267, \mathrm{C}_{5}=0.2397, \mathrm{H}=0.8568$, $\left.\mathrm{C}_{6}=-0.2727, \mathrm{C}_{7}=0.0513, \mathrm{C}_{8}=-0.5905\right) . \mathrm{M}_{\mathrm{w}}$ is the moment magnitude, and $\mathrm{R}$ is the closest distance to the fault $(\mathrm{km}) . \mathrm{F}_{\mathrm{NM}}$ and $\mathrm{F}_{\mathrm{RV}}$ represent the earthquake type $\left(\mathrm{F}_{\mathrm{NM}}=1\right.$
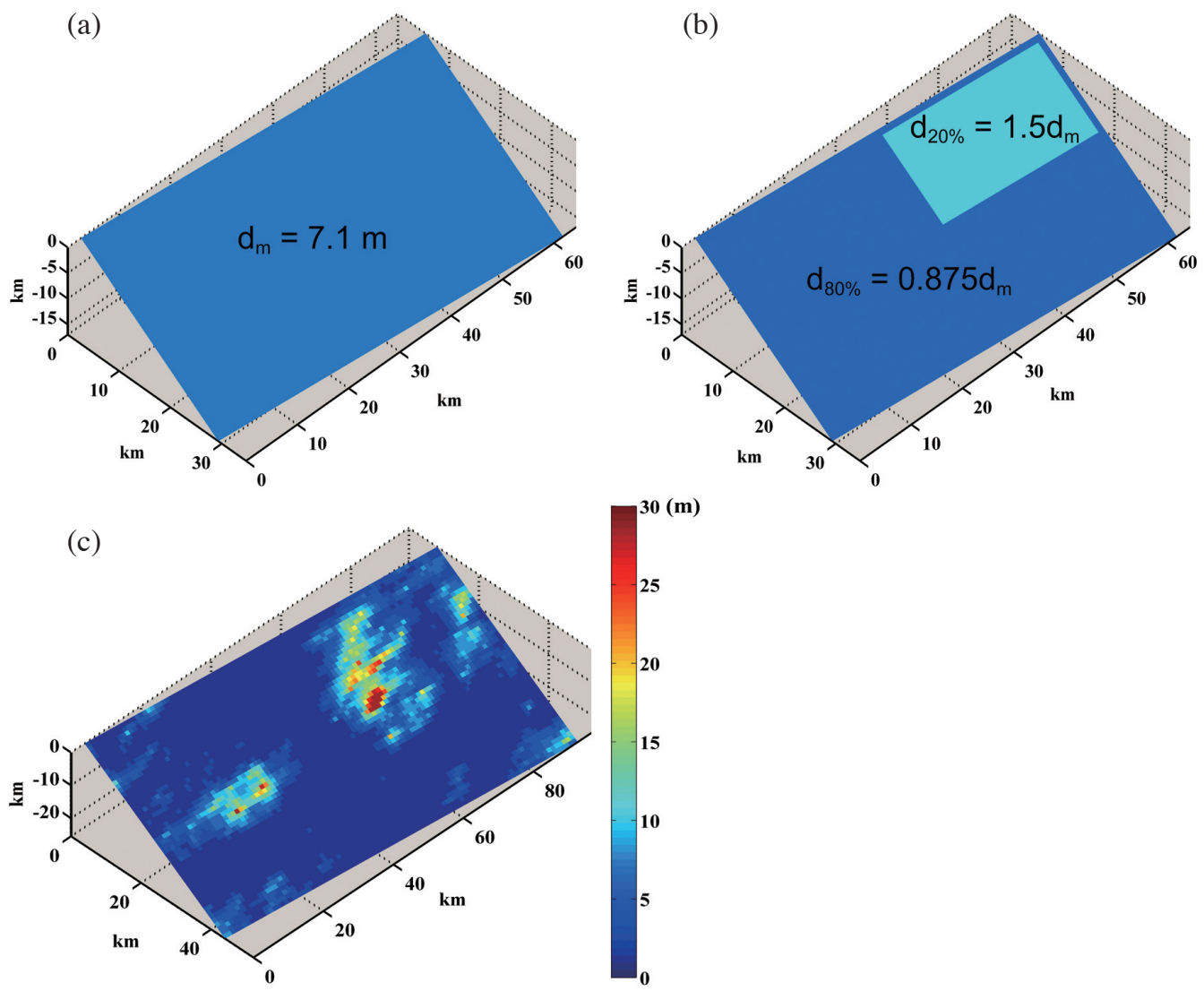

Fig. 4. Three compared source models of the scenario earthquake. (a) Fault plane with a mean slip of $7.1 \mathrm{~m}$ and effective length and width of 63 and $35 \mathrm{~km}$, respectively. (b) Fault plane with $20 \%$ asperity area, where the slip is 1.5 times the mean slip (10.65 m; $6.2 \mathrm{~m}$ in the other areas). Its length and width are the same as the effective length and width. (c) Fault plane with a stochastic slip distribution that follows the slip scaling obtained by Lee et al. (2016); the dimension of the source model is 1.5 times the effective length and width. (Color online only) 
Table 1. Vertical grid setting for the finite-difference mesh.

\begin{tabular}{c|ccccc}
\hline Depth range (km) & $0-6$ & $6-18$ & $18-30$ & $30-42$ & $42-60$ \\
\hline Number of grids & 35 & 35 & 26 & 18 & 24 \\
\hline Grid spacing (m) & $\begin{array}{c}171 \\
\text { constant }\end{array}$ & $\begin{array}{c}184-443 \\
\text { variable }\end{array}$ & $\begin{array}{c}462 \\
\text { constant }\end{array}$ & $\begin{array}{c}667 \\
\text { constant }\end{array}$ & $\begin{array}{c}783 \\
\text { constant }\end{array}$ \\
\hline
\end{tabular}

(a)

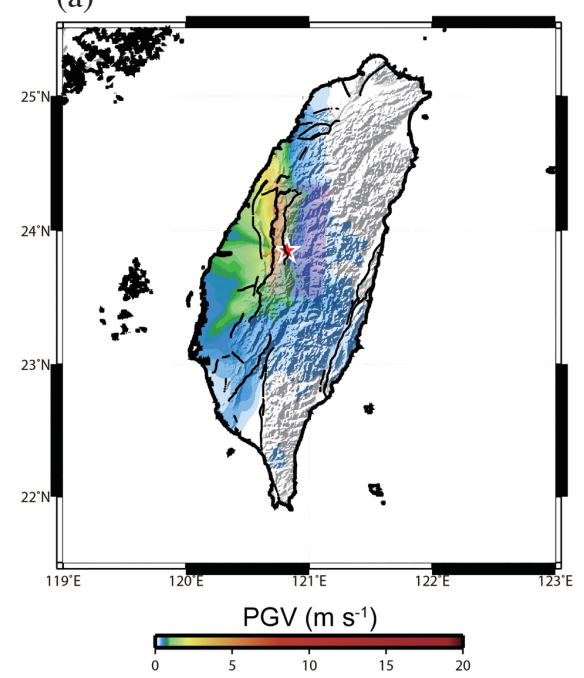

(b)

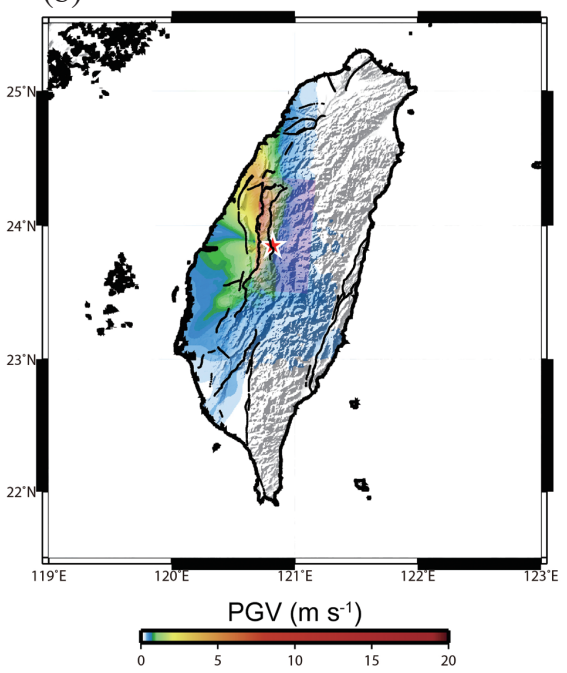

(c)

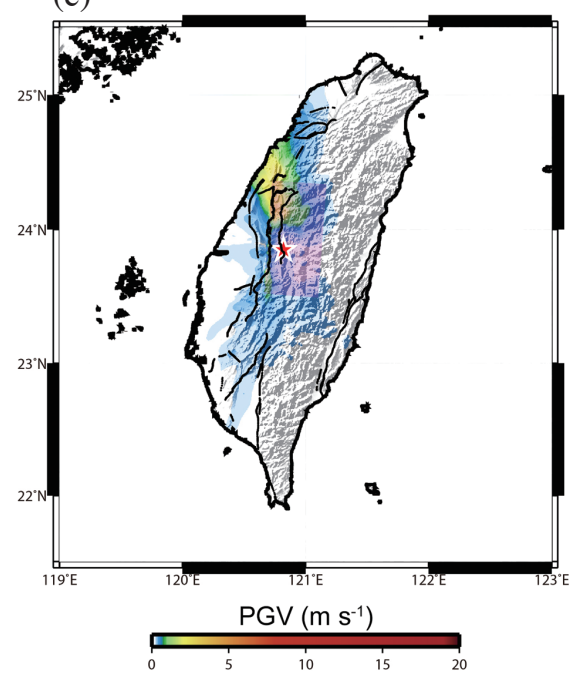

Fig. 5. Shaking maps of the PGV values calculated from the ground-motion simulations generated using three source models: the (a) mean slip, (b) characteristic asperity, and (c) stochastic-slip-scaling models. (Color online only)

and $\mathrm{F}_{\mathrm{RV}}=0$ for normal fault earthquake; $\mathrm{F}_{\mathrm{NM}}=0$ and $\mathrm{F}_{\mathrm{RV}}=1$ for reverse fault earthquake). Sites are classified into three generic classes depending on the average S-wave velocity of the top $30 \mathrm{~m}$ of the strata $\left(\mathrm{V}_{\mathrm{S} 30}\right): \mathrm{V}_{\mathrm{S} 30}=1130 \mathrm{~m} \mathrm{~s}^{-1}$ (hardrock site), $\mathrm{V}_{\mathrm{S} 30}=360 \mathrm{~m} \mathrm{~s}^{-1}$ (soft-rock or stiff-soil site), and $\mathrm{V}_{\mathrm{S} 30}=150 \mathrm{~m} \mathrm{~s}^{-1}$ (soft-soil site). Figures $6 \mathrm{a}-\mathrm{d}$ present the observed and simulated PGV values as a function of the closest distance to the fault and compared that with the GMPE of Eq. (5). The mean slip (Fig. 6a) and characteristic asperity (Fig. 6b) models overestimated the PGV, whereas the stochastic-slip-scaling model simulation (Fig. 6c) fit closely with the observations and the empirically obtained PGV.

A ground-motion residual is the logarithmic difference between the synthetic ground motion and the ground motion obtained from next-generation attenuation (NGA):

$\sigma=\sqrt{\frac{\sum_{i=1}^{n}\left[\log (s y n)_{i}-\log (o b s)_{i}\right]^{2}}{n-1}}$

which $\sigma$ is a general form representing the error (Kenney and Keeping 1962). The standard deviation of the mean slip, characteristic asperity, and stochastic-slip-scaling simulations are $0.48,0.46$, and 0.36 , respectively.

More synthetic ground motion data is needed to obtain a statistically significant result. Therefore, we simulated synthetic ground motions using 10 arbitrarily selected stochastic source models. In Fig. 6d the PGV values obtained using the GMPE developed by Lin et al. (2012) $\left(\mathrm{V}_{\mathrm{S} 30}=\right.$ $360 \mathrm{~m} \mathrm{~s}^{-1}$ ) are compared with the PGV values simulated using the 10 stochastic-slip-scaling models. The PGV residuals are defined as the difference between the synthetic ground motion and the GMPE-predicted ground motion (Strasser et al. 2009; Baumann and Dalguer 2014). The residuals from the synthetic PGVs lie within one standard deviation of the aforementioned GMPE.

\section{DISCUSSION}

Physics-based scenario source model simulation is crucial in generating near-fault synthetic ground motions (Baumann and Dalguer 2014). For a single characteristic source, the mean slip model is the simplest. Additionally, Irikura and Miyake (2011) hypothesized that the strong ground motion is related primarily to slip heterogeneity within the source rather than the average slip in the entire rupture area, and that the asperity area is approximately $22 \%$ of the rupture area. However, our simulation results indicated that the synthetic PGV values of the mean slip and characteristic asperity models overestimate the near-fault ground motion (distance $<30 \mathrm{~km}$ ). This overestimation might be caused by slip overconcentration in the source models. In general, most of the 
(a)

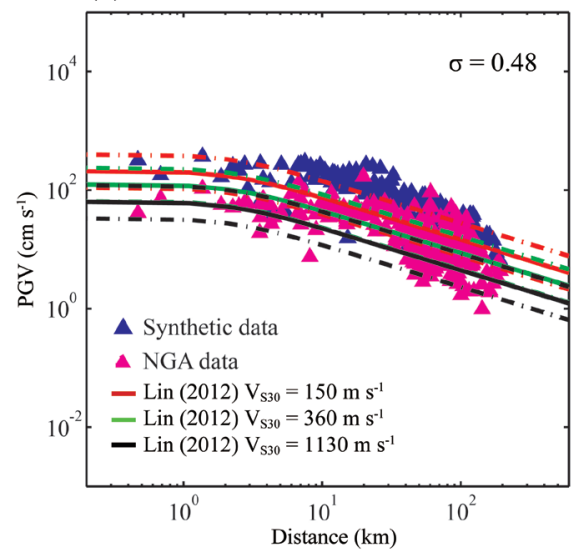

(c)

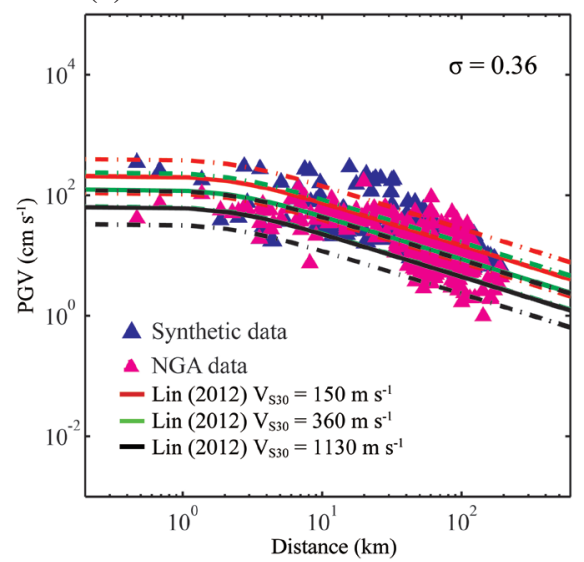

(b)

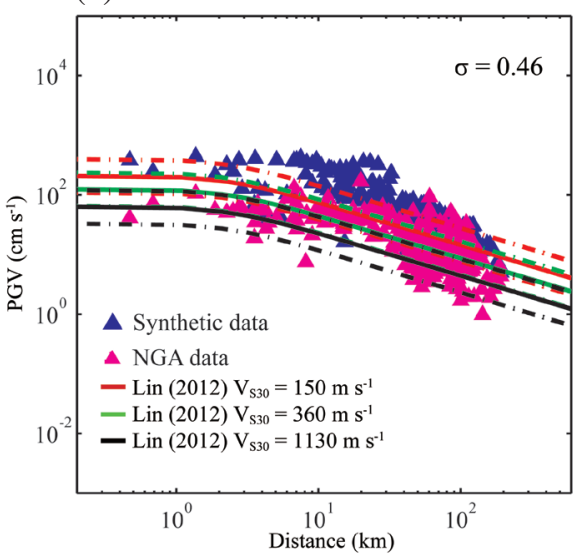

(d)

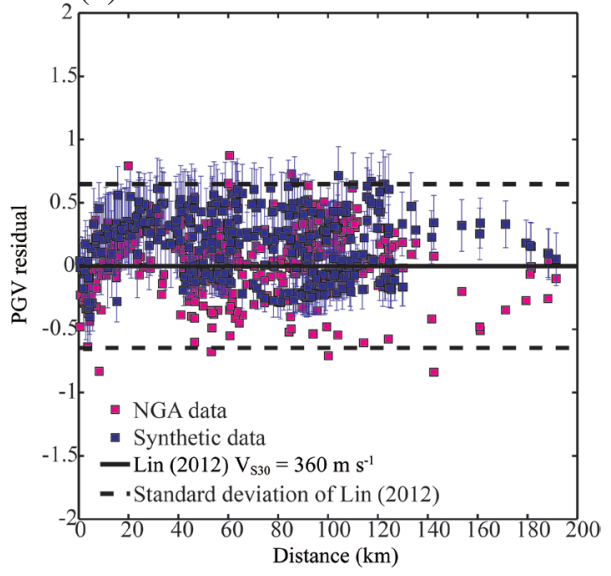

Fig. 6. PGV values obtained from the ground-motion simulations of the (a) mean slip, (b) characteristic asperity, and (c) stochastic-slip-scaling models. The blue and pink triangles are the PGV values obtained from the synthetic and NGA data, respectively. Solid lines represent the PGV values obtained empirically from the GMPE developed by Lin et al. (2012), and dashed lines represent one standard deviation of the GMPE. (d) Standard deviation (error bar) and mean (blue squares) of the PGV residuals for 10 stochastic models as a function of the closest distance to the fault. Residuals were calculated with respect to the mean GMPE values with $\mathrm{V}_{\mathrm{S} 30}=360 \mathrm{~m} \mathrm{~s}^{-1}$. (Color online only)

ground motions are from the effective rupture area, but a portion of the energy might be released from other areas in the fault plane. We scaled the slip area for characterizing the heterogeneous properties of the fault plane and applied the stochastic method for the slip-distribution spatial variation in the scenario earthquake model. The length and width of the stochastic model is 1.5 times the effective length and width. The stochastic-slip-scaling model proposed in this paper has low ground-motion residuals (Fig. 6). The synthetic PGV of the stochastic-slip-scaling model is comparable with the observed PGV and fits well with the GMPE proposed by Lin et al. (2012).

The degree of ground motion is usually expressed in terms of PGV or peak ground acceleration (PGA). The peak ground motion in synthetic seismograms lacks highfrequency energy content and the high-frequency content in our waveform simulations is limited (up to $0.8 \mathrm{~Hz}$ ); nevertheless, PGV is less sensitive to these high-frequency components (Baumann and Dalguer 2014). Therefore, synthetic ground motion measured in terms of $\mathrm{PGV}$ is appropriate for validating near-fault motion. In engineering and seismological applications, response spectral acceleration (SA) is often used to design structures, for which broadband synthetic ground motion might be required. The high-frequency content can be simulated by a stochastic synthetic ground motion (e.g., Berge et al. 1998; Pulido and Kubo 2004; Liu et al. 2006; Pulido and Dalguer 2009; Graves and Pitarka 2010; Mai et al. 2010; Irikura and Miyake 2011).

To assess the ground motions of future earthquakes, evaluating the seismic hazard is essential, particularly for critical structures, such as nuclear power plants and public infrastructure. Ground-motion simulation clarifies the relationship between the topography, directivity effect, and surface strong ground motion. The results of this study are useful for constructing slip distribution in scenario source models for ground-motion prediction and earthquake-hazard mitigation.

\section{CONCLUSIONS}

This study proposes a spatial stochastic model with 
slip scaling for ground-motion simulation. This study is the first to scale the slipped area in a stochastic model of a scenario earthquake. This study applied a 3D finite-difference algorithm to scenario earthquake models and compared the observed and simulated PGV values. The stochastic-slipscaling model, mean slip and characteristic asperity models were examined. The simulations were compared with the near-fault ground motion calculated using the GMPE. The proposed model fits well with the empirical attenuation equation. Predicting ground motion by simulating scenario earthquakes is essential for establishing NGA relationships and constructing a probabilistic seismic hazard map. The spatial stochastic model with finite fault slip scaling proposed in this study can serve as a reference for the seismological community in the ground-motion prediction of scenario earthquakes.

Acknowledgements The authors are grateful for research support from both the Ministry of Science and Technology (MOST) and the Department of Earth Sciences, National Central University, Taiwan, ROC. Thanks to Central Weather Bureau Seismological Network for providing high-quality seismic data. This research was supported by funded through MOST, with project grant number MOST 103-2116-M-008008-MY3 and the Taiwan Earthquake Research Center (TEC) funded through MOST, formerly National Science Council (NSC), with Taiwan Earthquake Model (TEM) project grant number MOST 105-2119-M-006-016. The TEC contribution number for this article is 00200 .

\section{REFERENCES}

Amante, C. and B. W. Eakins, 2009: ETOPO1 1 arc-minute global relief model: procedures, data sources and analysis. NOAA Technical Memorandum NESDIS NGDC-24. National Geophysical Data Center, NOAA, doi: 10.7289/V5C8276M. [Link]

Aochi, H. and S. Ide, 2009: Complexity in earthquake sequences controlled by multiscale heterogeneity in fault fracture energy. J. Geophys. Res., 114, B03305, doi: 10.1029/2008JB006034. [Link]

Aochi, H. and S. Ide, 2011: Conceptual multi-scale dynamic rupture model for the 2011 off the Pacific coast of Tohoku Earthquake. Earth Planets Space, 63, 761-765, doi: 10.5047/eps.2011.05.008. [Link]

Baumann, C. and L. A. Dalguer, 2014: Evaluating the compatibility of dynamic rupture-based synthetic ground motion with empirical ground-motion prediction equation. Bull. Seismol. Soc. Am., 104, 634-652, doi: 10.1785/0120130077. [Link]

Berge, C., J. C. Gariel, and P. Bernard, 1998: A very broadband stochastic source model used for near source strong motion prediction. Geophys. Res. Lett., 25, 1063-1066, doi: 10.1029/98GL00732. [Link]
Bracewell, R. N., 1986: The Fourier Transform and Its Applications, McGraw-Hill, New York, 474 pp.

Central Geological Survey (CGS), 1999: Report of the Geological Survey of the 1999 Chi-Chi Earthquake, Central Geological Survey, Taipei, Taiwan. (in Chinese)

Frankel, A., 1991: High-frequency spectral falloff of earthquakes, fractal dimension of complex rupture, $b$ value, and the scaling of strength on faults. J. Geophys. Res., 96, 6291-6302, doi: 10.1029/91JB00237. [Link]

Graves, R. W . and A. Pitarka, 2010: Broadband ground-motion simulation using a hybrid approach. Bull. Seismol. Soc. Am., 100, 2095-2123, doi: 10.1785/0120100057. [Link]

Herrero, A. and P. Bernard, 1994: A kinematic self-similar rupture process for earthquakes. Bull. Seismol. Soc. Am., 84, 1216-1228.

Hsieh, M. C., L. Zhao, and K. F. Ma, 2014: Efficient waveform inversion for average earthquake rupture in threedimensional structures. Geophys. J. Int., 198, 12791292, doi: 10.1093/gji/ggu209. [Link]

Ide, S. and H. Aochi, 2005: Earthquakes as multiscale dynamic ruptures with heterogeneous fracture surface energy. J. Geophys. Res., 110, B11303, doi: 10.1029/2004JB003591. [Link]

Ide, S. and H. Aochi, 2013: Historical seismicity and dynamic rupture process of the 2011 Tohoku-Oki earthquake. Tectonophysics, 600, 1-13, doi: 10.1016/j.tecto.2012.10.018. [Link]

Irikura, K. and H. Miyake, 2011: Recipe for predicting strong ground motion from crustal earthquake scenarios. Pure Appl. Geophys., 168, 85-104, doi: 10.1007/ s00024-010-0150-9. [Link]

Kenney, J. F. and E. S. Keeping, 1962: Linear regression and correlation. Mathematics of Statistics, $3^{\text {rd }}$ edition, NJ: Van Nostrand, Princeton, 252-285.

Klinger, Y., 2010: Relation between continental strikeslip earthquake segmentation and thickness of the crust. J. Geophys. Res., 115, B07306, doi: 10.1029/2009JB006550. [Link]

Kuo-Chen, H., F. T. Wu, and S. W. Roecker, 2012: Threedimensional $\mathrm{P}$ velocity structures of the lithosphere beneath Taiwan from the analysis of TAIGER and related seismic data sets. J. Geophys. Res., 117, B06306, doi: 10.1029/2011JB009108. [Link]

Lee, Y. T., K. F. Ma, and Y. T. Yen, 2016: Heterogeneous slip distribution self-similarity on a fault surface. Terr. Atmos. Ocean. Sci., 27, 181-193, doi: 10.3319/ TAO.2015.11.05.01(T). [Link]

Liao, Y. W., Y. T. Yen, S. J. Lee, and K. F. Ma, 2016: 1909 Taipei earthquake ground motion simulation. Terr. Atmos. Ocean. Sci., 27, 415-430, doi: 10.3319/ TAO.2016.03.02.01(TEM). [Link]

Lin, P. S., P. S. Hsie, Y. R. Lee, C. T. Cheng, and K. S. Shao, 2012: The research of probabilistic seismic hazard 
analysis and geological survey of nuclear power plant: Construction of ground motion prediction equation for response spectra. Commission Report of the Institute of Nuclear Energy Research, Atomic Energy Council, Executive Yuan. (in Chinese)

Liu, P., R. J. Archuleta, and S. H. Hartzell, 2006: Prediction of broadband ground-motion time histories: Hybrid low/high-frequency method with correlated random source parameters. Bull. Seismol. Soc. Am., 96, 21182130, doi: 10.1785/0120060036. [Link]

Ma, K. F., J. Mori, S. J. Lee, S. B. Yu, 2001: Spatial and temporal distribution of slip for the 1999 Chi-Chi, Taiwan, earthquake. Bull. Seismol. Soc. Am., 91, 10691087, doi: 10.1785/0120000728. [Link]

Mai, P. M. and G. C. Beroza, 2000: Source scaling properties from finite-fault-rupture models. Bull.Seismol.Soc. Am., 90, 604-615, doi: 10.1785/0119990126. [Link]

Mai, P. M. and G. C Beroza, 2002: A spatial random field model to characterize complexity in earthquake slip. J. Geophys. Res., 107, doi: 10.1029/2001JB000588. [Link]

Mai, P. M., W. Imperatori, and K. B. Olsen, 2010: Hybrid broadband ground-motion simulations: Combining longperiod deterministic synthetics with high-frequency multiple $S$-to-S backscattering. Bull. Seismol. Soc. Am., 100, 2124-2142, doi: 10.1785/0120080194. [Link]

Manighetti, I., M. Campillo, C. Sammis, P. M. Mai, and G. King, 2005: Evidence for self-similar, triangular slip distributions on earthquakes: Implications for earthquake and fault mechanics. J. Geophys. Res., 110, B05302, doi: 10.1029/2004JB003174. [Link]

Manighetti, I., M. Campillo, S. Bouley, and F. Cotton, 2007: Earthquake scaling, fault segmentation, and structural maturity. Earth Planet. Sci. Lett., 253, 429-438, doi: 10.1016/j.epsl.2006.11.004. [Link]

Murotani, S., H. Miyake, and K. Koketsu, 2008: Scaling of characterized slip models for plate-boundary earthquakes. Earth Planets Space, 60, 987-991, doi: 10.1186/BF03352855. [Link]

Pegler, G. and S. Das, 1996: Analysis of the relationship between seismic moment and fault length for large crustal strike-slip earthquakes between 1977-92. Geophys. Res. Lett., 23, 905-908, doi: 10.1029/96GL00963. [Link]

Pulido, N. and L. A. Dalguer, 2009: Estimation of the high-frequency radiation of the 2000 Tottori (Japan) earthquake based on a dynamic model of fault rup- ture: Application to the strong ground motion simulation. Bull. Seismol. Soc. Am., 99, 2305-2322, doi: 10.1785/0120080165. [Link]

Pulido, N. and T. Kubo, 2004: Near-fault strong motion complexity of the 2000 Tottori earthquake (Japan) from a broadband source asperity model. Tectonophysics, $\mathbf{3 9 0}$, 177-192, doi: 10.1016/j.tecto.2004.03.032. [Link]

Romanowicz, B., 1992: Strike-slip earthquakes on quasivertical transcurrent faults: Inferences for general scaling relations. Geophys. Res. Lett., 19, 481-484, doi: 10.1029/92GL00265. [Link]

Scholz, C. H., 1994: A reappraisal of large earthquake scaling. Bull. Seismol. Soc. Am., 84, 215-218.

Somerville, P., K. Irikura, R. Graves, S. Sawada, D. Wald, N. Abrahamson, Y. Iwasaki, T. Kagawa, N. Smith, and A. Kowada, 1999: Characterizing crustal earthquake slip models for the prediction of strong ground motion. Seismol. Res. Lett., 70, 59-80, doi: 10.1785/ $\operatorname{gssrl} .70 .1 .59$. [Link]

Strasser, F. O., N. A. Abrahamson, and J. J. Bommer, 2009: Sigma: Issues, insights, and challenges. Seismol. Res. Lett., 80, 40-56, doi: 10.1785/gssrl.80.1.40. [Link]

Wang, J. H. and S. S. Ou, 1998: On scaling of earthquake faults. Bull. Seismol. Soc. Am., 88, 758-766.

Wells, D. L. and K. J. Coppersmith, 1994: New empirical relationships among magnitude, rupture length, rupture width, rupture area, and surface displacement. Bull. Seismol. Soc. Am., 84, 974-1002.

Wesnousky, S. G., 2008: Displacement and geometrical characteristics of earthquake surface ruptures: Issues and implications for seismic-hazard analysis and the process of earthquake rupture. Bull. Seismol. Soc. Am., 98, 1609-1632, doi: 10.1785/0120070111. [Link]

Yen, Y. T. and K. F. Ma, 2011: Source-scaling relationship for $M$ 4.6-8.9 earthquakes, specifically for earthquakes in the collision zone of Taiwan. Bull. Seismol. Soc. Am., 101, 464-481, doi: 10.1785/0120100046. [Link]

Wen, Y. Y., Y. T. Yen, S. Wen, S. J. Lee, C. H. Kuo, and Y. Y. Lin, 2016: Hybrid ground motion simulation for the $2013 \mathrm{M}_{\mathrm{L}} 6.4$ Ruisui, Taiwan earthquake. Terr. Atmos. Ocean. Sci., 27, 407-414, doi: 10.3319/ TAO.2015.10.30.01(TEM). [Link]

Zhang, W. and X. Chen, 2006: Traction image method for irregular free surface boundaries in finite difference seismic wave simulation. Geophys. J. Int., 167, 337353, doi: 10.1111/j.1365-246X.2006.03113.x. [Link] 